\title{
INVESTIGATION OF THE LIGHTNING ARRESTER OPERATION IN ELECTRIC POWER DISTRIBUTION NETWORK
}

\author{
P. 0. Oluseyi ${ }^{1,}{ }^{*}$, T. 0. Akinbulire ${ }^{2}$ and 0. Amahian ${ }^{3}$ \\ 1, 2, 3 DEPARTMENT OF EleCtRICAL/ELECTRONICS ENGINEERING, UNIVERSITY OF LAGOS, LAGOS STATE. NIGERIA \\ E-mail addresses: ${ }^{1}$ poluseyi@unilag.edu.ng, ${ }^{2}$ takinbulire@unilag.edu.ng, ${ }^{3}$ oamahian@gmail.com
}

\begin{abstract}
Lightning phenomenon has resulted into several losses to both supply-side and load-side of the electricity infrastructure. Quite a handful of research has investigated strategies for its mitigation. This work is an application of the Fernandez-Diaz arrester model to the section of Eko Distribution network. The procedure involves simulation of the network in respect of the influence of the surges and surge arresters using MATLAB/SIMULINK. The study reveals that whenever lightning strikes, the resulting overvoltage causes distortion to the voltage waveform, as well as the current waveform. This indicates the presence of harmonics. Meanwhile, with the installation of the arresters, the overvoltage reduces by $86 \%$ at the nearest node of installation. However, at the other nodes within the same branch, the installed arrester attenuated the surge overvoltage by approximately $60 \%$. This suggests that more arresters need to be installed at other nodes along the branch in order to eliminate the occurrence of overvoltage. Moreover, the study reveals that a surge arrester installed at one of the two branches of the network has negligible effect in attenuating voltage surge at the other branch of the same network
\end{abstract}

\section{Keywords. Lightning arrester, substation, overvoltage, attenuation, harmonics}

\section{INTRODUCTION}

The occurrence of lightning has been revealed as one of the major cause of loss of service in transmission and distribution networks $[1,2]$. The literature has established it that the highest densities and extremely destructive thunderstorm with lightning strokes occur in the tropical region $[3,4]$. More so the percentage of electrical and electronic facilities that are subjected to failure through the activities of lightning and its overvoltage phenomenon is on the increase in Nigeria and elsewhere [5]. Thus there is an increasing demand for the overvoltage protection against lightning occurrence in distribution network because it degrades the power quality of consumer service. Meanwhile, customer service value is crucial in the new dispensation of deregulation. Some of the ways this can be done include insulation coordination, switching action buffer as well as very fast discharge of ions in the atmosphere. Like any other tropical nation, Nigeria has an average of 28 lightning per minute. Hence, any structure can be struck in the process, though high structure has more propensity of lightning strikes than lower ones. In any event that an electrical line is struck, there is the tendency to suffer outage from such lightning strokes $[4,5]$.

Lightning is a major source of faults in overhead lines and other substation equipment. It is essential to mitigate its effects to improve power system stability and quality. As a way of definition, lightning is a powerful, sudden, electrostatic discharge accompanied by thunder that occurs during a thunder storm [3-5]. Lightning arresters protect major equipment such as transformers, rotating machines, shunt reactors, as well as loads against overvoltage. The discharge could travel between the electrically charged regions within a thundercloud, or between a cloud and a cloud or between a cloud and the surface of the planet [6]. Lightning strikes on overhead lines are part of the reasons for unscheduled power supply interruptions which is registered as forced outage. Studies show that during the year, especially during the rainy season, transient surges are experienced in power networks especially when the lightning arresters in the network are by-passed or faulty $[7,8]$.

Lightning is destructive in nature. It often results in insulation breakdown, shattering of insulators or burnout of power equipment especially at the outdoor 
substation, when not properly protected. Its undesirable effect on personnel and even properties is valued at millions of hard currencies is enormous. From various available designs, the electric power industry experts report that an average of $30-40 \%$ of all outages is linked to the lightning-related events [912]. This phenomenon accentuates an in-depth study of lightning operation in power distribution networks. The most commonly used device for protection of equipment at the substations is the lightning arrester and it is connected between the line and earth, i.e. parallel with the equipment to be protected [9]. The substations can simply be described as a combination of apparatus that transforms electrical energy from one form or level to another form with the provision of facilities for switching. Lightning arresters help prevent damage to apparatus due to high voltages [10]. The arrester provides a low impedance path to ground for the current from lightning stroke or transient voltages and then restores to normal operating conditions [11]. Lightning arresters are used primarily to protect major equipment like transformers, rotating machines, shunt reactors and even the entire substation. Lightning arresters are connected between the line and earth at the substation and power stations $[10,13,14]$.

Several approaches have been adopted for mitigating the influence of lightning occurrence on the power system. But hardly was any found to have considered the radial nature of the networks as typified by the Nigeria's scenario [2]. Thus, the main thrust of this paper is to analyze a typical distribution network from Nigeria, to proffer appropriate remedial action for ensuring continuity of service. In other words, the aims of this research are:

i) To model the surge phenomenon and evaluate the effect of installed lightning arresters with regards to attenuation of surge in network.

ii) To develop a model to represent the distribution substation using MATLAB/SIMULINK

iii) To extend the Fernandez-Diaz model for arresters in a network.

The rest of the paper is organized as follows: Section 2 is the problem formulation. Section 3 is mathematical method of solution, while the case study of AmuwoOdofin in Eko Distribution company is presented in section 4. The results of implementation of the case study is in section 5 whilst its discussion is form the section 6 and the concluding remarks constitute section 7 .

\section{PROBLEM FORMULATION}

Even though electricity was first generated in Nigeria in 1898, but the network connection of both transmission and distribution system is still very fragile, poorly coordinated and without any sophistication or creativity. This led to the continuous introduction of electric power industry reforms, whereby, the business of generation, transmission and distribution, which were altogether under single umbrella of the National Electric Power Authority (NEPA), has hitherto been unbundled into separate subsectors of the power industry. Because of the Electric Power Sector Reform (EPSR) bill, that was signed into the law in March 2005, 11 distribution companies (DISCOs) were formed [2]. Due to the enormity of consumption in the Lagos metropolis, two of these companies are in Lagos. They are namely Eko Electricity Distribution Plc (EKEDP) and Ikeja Electricity Distribution Plc (IKEDP) [2]. These DISCOs were further privatized on November 1, 2013, thus completing the cycle of reform efforts in Nigeria that began almost a decade ago. Each DISCO is responsible for the electricity distribution activities in demarcated geographical zones (license areas) of Nigeria. EKEDP covers the license area of southern part of Lagos state and Agbara in Ogun state. For the ease of operations and division of work, the license area of EKEDP is segmented into 3 circles and 8 districts. These include the West circle comprising Agbara, Ojo and Festac districts; Central circle comprising Ijora, Mushin (also covers Orile areas) and Apapa districts; East circle comprising Lekki (also covers Ibeju areas) and Island (also covers Ajele areas) districts.

EKEDP is supplied with electricity from the following two transmission sources; Akangba (330/132kV) and Ajah $(330 / 132 \mathrm{kV})$ channelled through 10 Nos. $132 / 33 \mathrm{kV}$ transmission stations. There are 40 injection substations with a total installed capacity of 1137.5MVA. some of these substations are susceptible to lightning surge incidences which could militate against system reliability [17]. This capacity and system reliability will further increase with various NIPP projects in EKEDP's high tension network (HT $33 \mathrm{kV} \& 11 \mathrm{kV}$ ). There are over 6000 distribution substations with total installed capacity of around 2500 MVA. This is good enough to serve a present base of around 0.4 million customers and existing load demand on the network $[2,5]$. The elements of the EKEDP distribution substation include lines, earth, ground wires, distribution transformers, auxiliary transformers, instrument transformers, disconnect switches, circuit breakers, fuses, contactors, relays, lightning arresters, reactors, towers/poles, control 
room, guard hut, distribution substation officers (DSO), security fence and safety devices [5].

Lightning strike has a destructive nature - it causes insulation breakdown or burnout of equipment at the substation, when the equipment is not properly protected which ultimately results in downtime of the network [11, 16]. EKEDC experiences quite a lot of surges during the rainy season. Lightning strikes have recorded significant cases in the distribution network. Amuwo distribution substation is taken as the object of investigation because of severity, as well as impact of lightning with regards to maintenance cost. The need for adaptation of surge arrester for mitigation against influence of surge, the number of arresters and the points of installation in such a substation is key [14]. There are several methods of surge arrester models; such as the IEEE model, Popov Model and the Fernandez-Diaz model [15]. But the latter is going to be adapted for the Nigeria's network due to lack of adequate data which gave room to establishing the calculations on a few assumptions [16]. While it is necessary to install surge arrester at many points to suppress lightning surges, the cost implication of purchasing and installing the arresters should be considered.

\section{METHOD}

In the electric networks, the prevalent condition in network subjected to thunderstorm is the sudden excursion of voltage waveform into an abnormal level, hence the arrester is designed to mitigate the surges arising from switching, overvoltage and other such actions that are dependent on surge occurrence. Thus, the surge arrester remains the most commonly used tool for mitigating the influence of surges in distribution networks $[18,19]$. The network has been modelled using several approaches [12, 16, 17]. Figure 1 is an adaptation of the Fernandez-Diaz arrester model for this work. Fernandez-Diaz model is adopted because it gives the closest characteristics of a practical arrester [20, 21]. Furthermore, MATLAB/SIMULINK recognizes and uses the model. $\mathrm{A}_{0}$

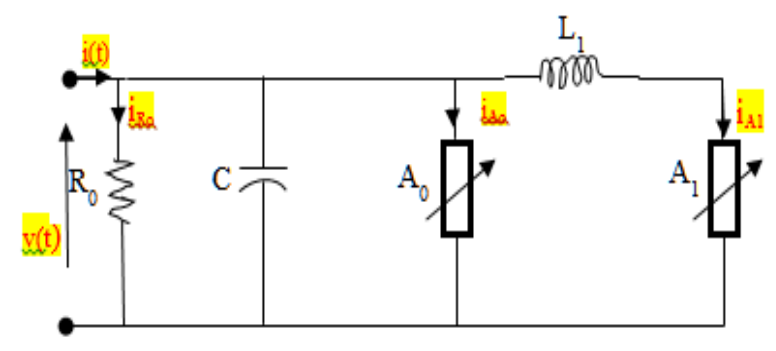

Figure 1: Fernandez-Diaz arrester model
The non-linear resistors, $A_{0}$ and $A_{1}$ are connected in parallel and separated by inductance, $\mathrm{L}_{1}$. Capacitance, $\mathrm{C}$ is the value of the terminal capacitor and $\mathrm{R}$ represents arrester's resistance. It is analyzed as follows: The current-voltage equations for the model can be written as follows:

$$
\begin{gathered}
v(t)-L_{0} \frac{d\left[i_{A 0}(t)-i_{A 1}(t)\right]}{d t}-L_{1} \frac{d i_{A 1}(t)}{d t}-v_{A 1}(t)=0 \\
v(t)-L_{0} \frac{d\left[i_{A 0}(t)-i_{A 1}(t)\right]}{d t}-v_{A 0}(t)=0 \\
v(t)-R_{0} i_{R 0}(t)=0 \\
i(t)-i_{R 0}(t)-i_{A 0}(t)-i_{A 1}(t)=0
\end{gathered}
$$

The line inductance,

$$
L=\frac{2}{5} \frac{V r / T_{1}-V_{S S}}{V_{r s} / T_{1}} V_{r}[\mu H]
$$

The line capacitance

$$
C=\frac{1}{55} \frac{V_{r s} /_{T_{1}}-V_{S S}}{V_{r s} / T_{s}} V_{r}
$$

Where:

$V r$ is the rated voltage, $V_{S S}$ is the residual voltage at $0.5 \mathrm{kA}$ current surge switching, $V_{r S}$ is the residual voltage at $0.5 \mathrm{kA}$ current surge switching, $\mathrm{T}_{\mathrm{s}}$ is the switching time, $\mathrm{T}_{1}$ is the rise time (i.e. the time from the beginning of the surge to the peak value), $U_{r 8 / 20}$ is the residual voltage at $10 \mathrm{kA}$ current surge with $8 / 20 \mu \mathrm{s}$ shape in $\mathrm{Kv}, V_{r 1 / T 1}$ is the residual voltage at $10 \mathrm{kA}$ fast front current surge $\left(1 / \mathrm{T}_{1} \mu \mathrm{s}\right), V_{r 8 / 20}$ is the residual voltage at $10 \mathrm{kA}$ current surge with $8 / 20 \mu$ shape, $R_{0}=1 \mathrm{M} \Omega$ is introduced to avoid numerical instabilities

The mathematical expression for the surge voltage is given as:

$$
\begin{array}{cc}
V(t)=1 & \text { for } 0 \leq t<0.3 \\
V(t)=1+V_{m} e^{-2 t} & \text { for } t=0.3 \leq 0.5 \\
V(t)=1 \quad \text { for } t=0.5<t \leq 1.0
\end{array}
$$

The surge voltage is modelled in MATLAB environment. This is embedded in a programmable voltage source installed in the SIMULINK environment. The output of the program is embedded in the simulated SIMULINK model.

\section{CASE STUDY}

The operation of surge arresters in Amuwo distribution substation is investigated through a model implemented using MATLAB/SIMULINK. This is explained in Figure 2.

\section{RESULTS}

Prior to the introduction of surge into the network by lightning activities, the voltage waveform captured at 


\section{Investigation of the Lightning ARrester Operation In Electric Power Distribution Network P. O. Oluseyi et al}

the primary side of transformer $\mathrm{T} 1$ is completely sinusoidal and has a magnitude of 1.0 p.u. .as shown in equation 7. However, when lightning strikes the substation at the $33 \mathrm{kV}$ (secondary) side, the voltage waveform captured at the transformer primary is shown in Figure 3. Its primary voltage rose abruptly from $1.0 \mathrm{pu}$ to $1.7 \mathrm{p} . \mathrm{u}$. at time 0.3 seconds, decreased progressively till time 0.5 seconds where it returned to 1.0p.u. This abrupt rise of the voltage is very dangerous to the effective operation of the transformer. It can cause insulation breakdown or melting of the coils.

Figure 4 below shows that the waveform captured when lightning strikes is also distorted. This implies that harmonics, which are signals at multiple of the fundamental frequency are contained in the voltage. These harmonics also constitute another problem that needs to be eliminated from the voltage signal. Figure 5 displays the resulting voltage waveform when lightning strike occurs. It is presented in magnitude form.

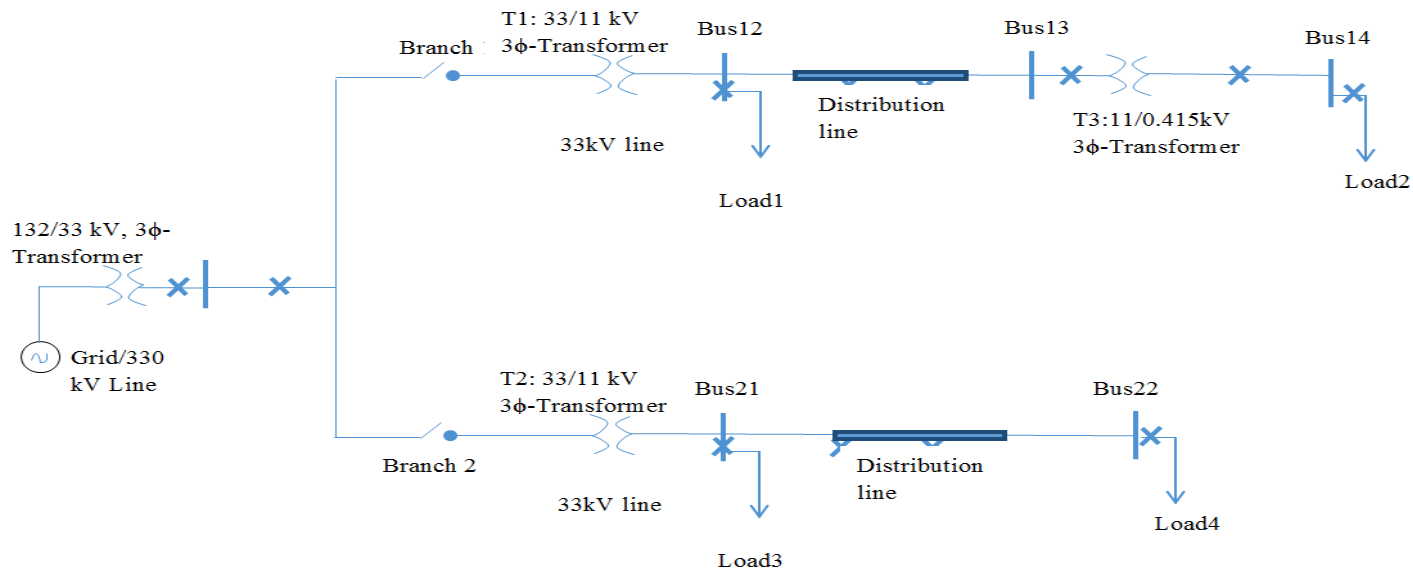

Figure 2: Electrical connection of the Amuwo-Odofin Substation

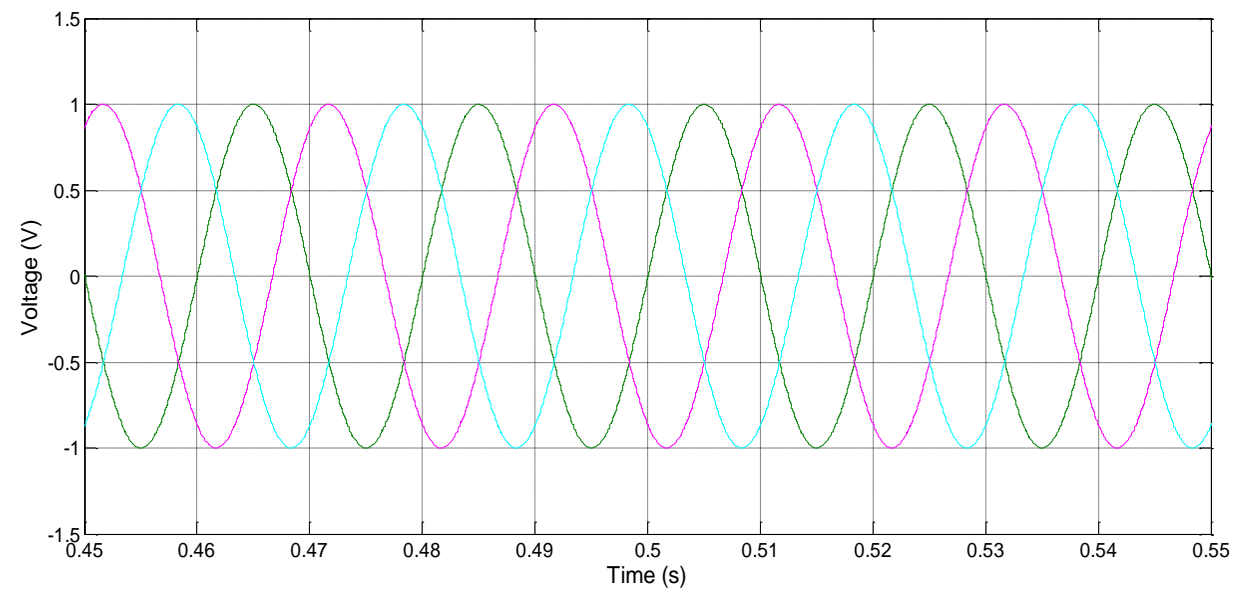

Figure 3: Voltage waveform before lightning strike

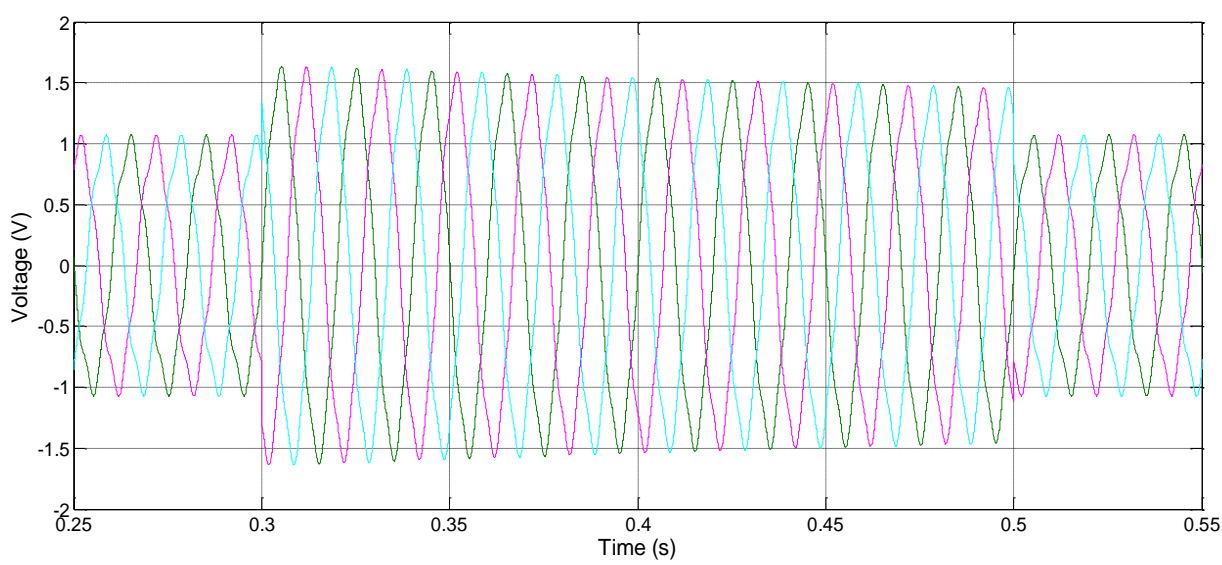

Figure 4: Voltage waveform when lightning strikes (without arresters) 


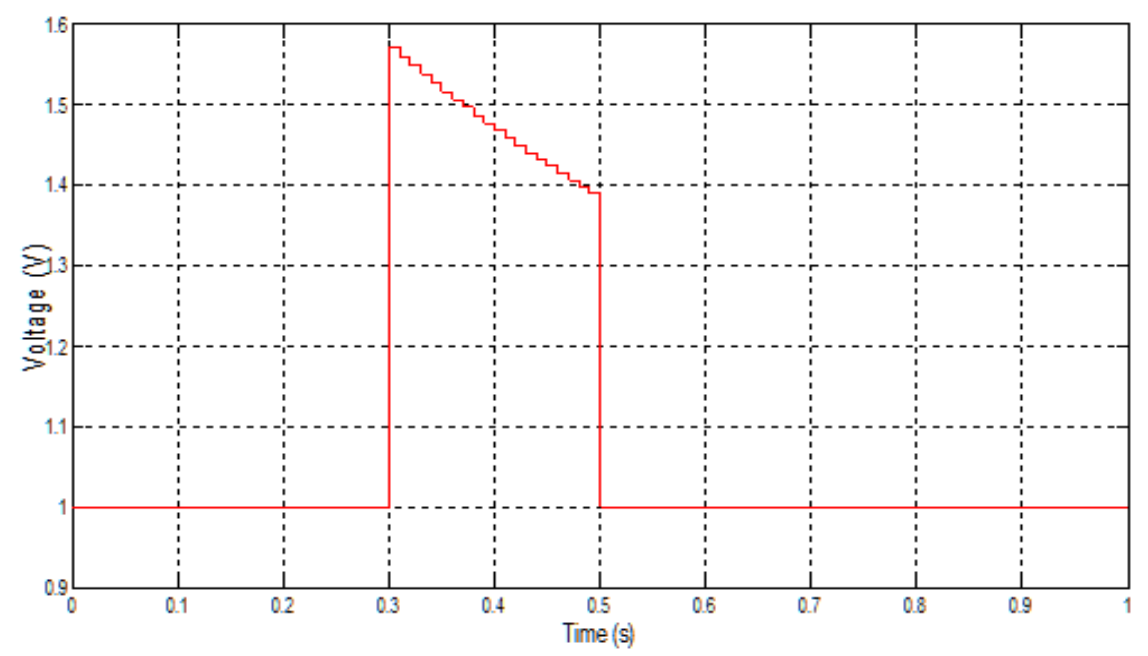

Figure 5: Voltage Magnitude when lightning strikes (without arresters)

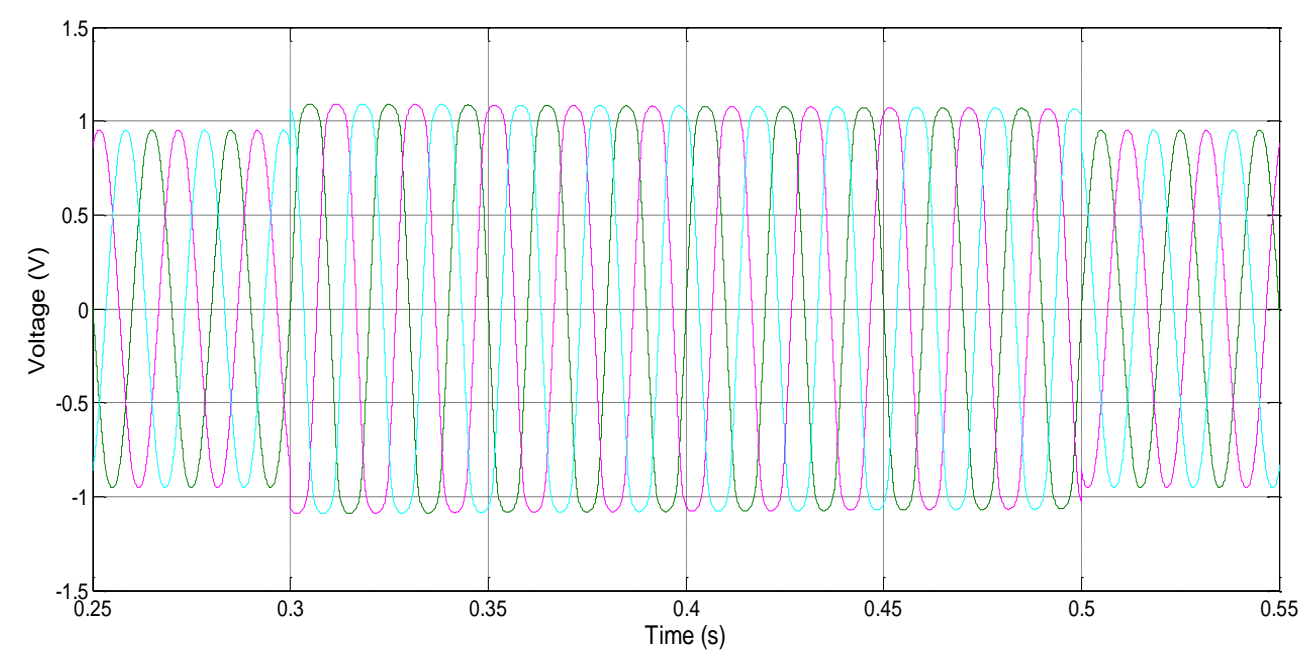

Figure 6: Voltage waveform when lightning strikes (with arresters)

Meanwhile, when the arrester is installed, the voltage waveform across the arrester is captured as shown in Figure 6. The figure shows that no residual voltage is recorded across the arrester till the voltage surge caused by lightning strike occurs. The figure is a view of the recorded voltage and shows that voltage across the arrester is slightly distorted.

Meanwhile the voltage across the arrester before the advent of the lightning strike is as displayed in Figure 7. It is obvious from this waveform that when the system operates under the influence of harmonic distortion during the incidence of the lightning occurrence; it introduces disturbances that impact the power quality of the system (see Figure 6).

Figure 8 below shows the current that flows through the arrester. It indicates that no current flows through the arrester until the lightning strikes. Besides, the figure further displays that the quantity of current that passes through the arrester at the point of lightning strike is large.

\section{DISCUSSION OF RESULTS}

When the travelling waves produced by lightning hit the windings of the transformer, it causes considerable damage. The inductance of the windings then opposes any sudden passage of electricity charge through it. Therefore, the electric charges "piles up" against the transformer (or generator). This induces such an excessive pressure between the windings that the insulation may breakdown, resulting in the production of arc. Also, the travelling waves produced by lightning surges can shatter insulators and wreck poles.

Whenever lightning strikes at any point in the network, it propagates from that point of incidence to other parts of the network. The propagation is such that the voltage surge magnitude increases as the voltage level decreases. This implies that consumer loads located at the low voltage levels will experience the highest effect of any lightning strike. 
It was observed that when lightning strikes in the substation, the resulting voltage and current waveforms are distorted. This indicates that harmonics have been injected to the network by the lightning strike. The prominent harmonics captured in the voltage waveform are the third and fifth harmonics. In a grounded distribution transformer network, the third harmonic can be removed but the fifth harmonics cannot be removed by the grounding. The fifth harmonic can only be removed by installing a harmonic filter and this implies additional cost to the utility. The resulting harmonics can cause transformer overheating, insulation overheating and other undesirable effects.

Moreover, it was found that the installed surge arrester can attenuate overvoltage caused by lightning by over $85 \%$ at the location of the arrester. Overvoltage caused at other downstream part of the arrester is also attenuated but the attenuation efficiency is approximately $60 \%$ at all downstream points. Since there is still considerable overvoltage at those downstream points, there is a need to install more surge arresters at more points to ensure a higher attenuation factor.

The simulated results indicate that a surge arrester installed at one branch of the network has virtually no effect in attenuating overvoltage caused by lightning strike in the other branch. Hence each of the two branches of the network should have at least two surge arresters installed at separate locations. Furthermore, the study showed that no current passes through the arrester prior to overvoltage in the network.

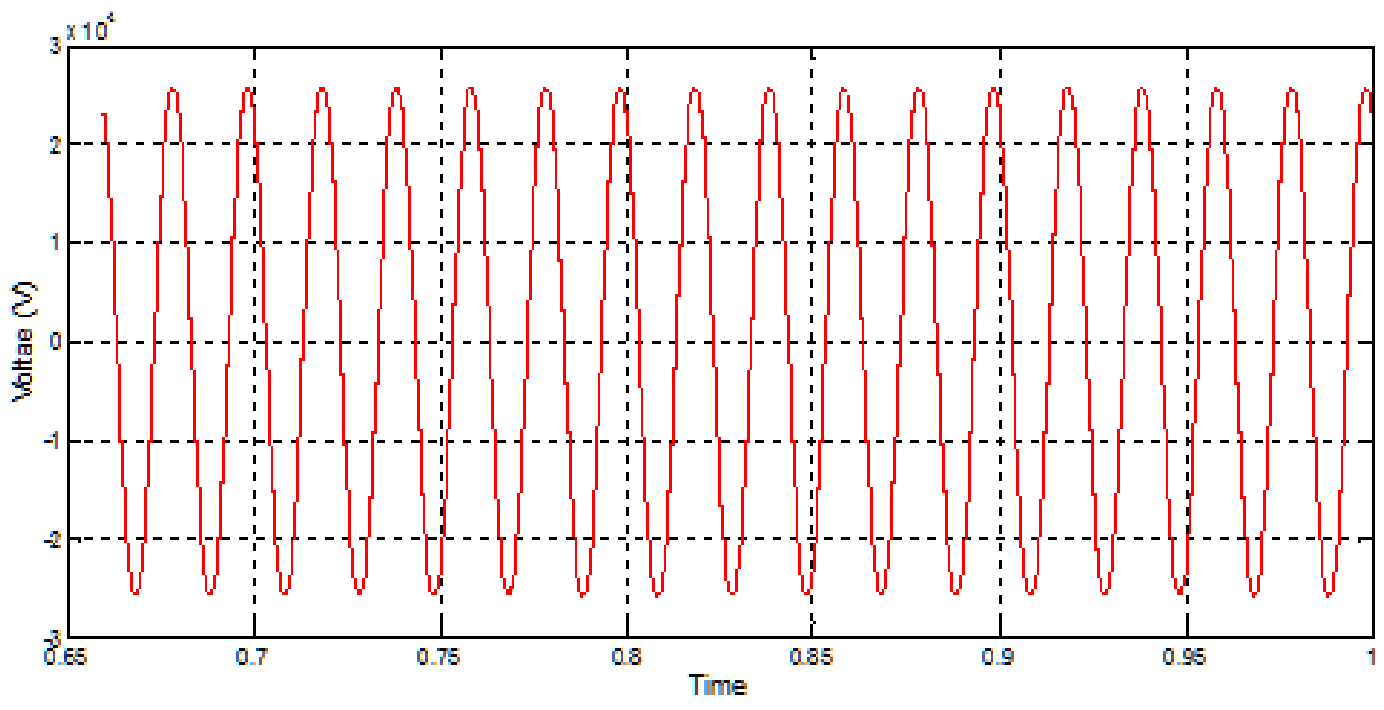

Figure 7: Voltage across the arrester after installation

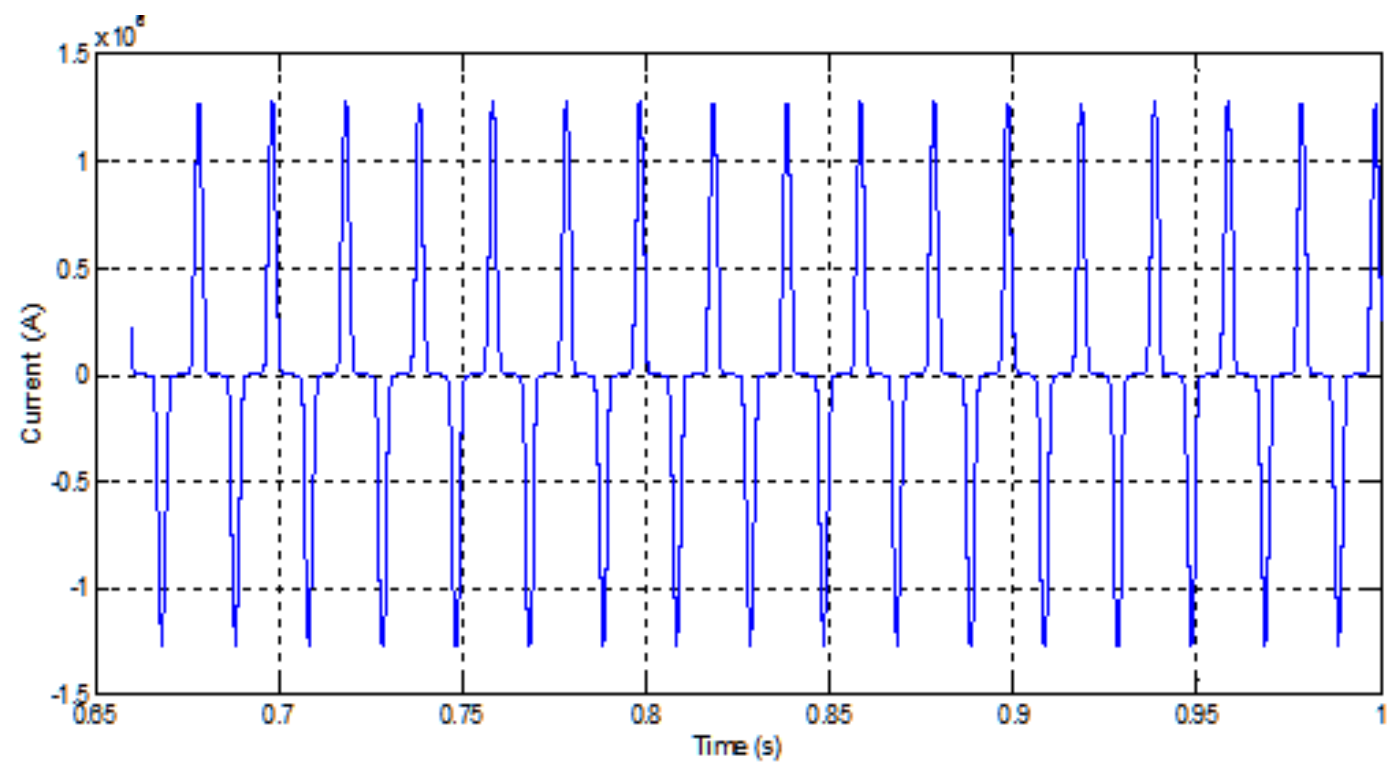

Figure 8: Current through the arrester 


\section{CONCLUSION}

It has been discovered that the lightning strikes at any node in the network propagates from node of incidence to other parts of the network. It has also been established that the propagation is such that the voltage surge magnitude increases as the voltage level decreases. Hence, whenever the lightning strikes the electrical equipment in the substation, it generates resultant voltage and current waveforms that experience distortion. It is noted that this is primarily due to the injection of harmonics into the network; as induced by lightning strikes. However, with the installation of the surge arresters; it was discovered that there was a delay in the current passage through the arrester after the occurrence of the lightning strike. This is attributed to the charging procedure associated with the electrical circuit of the arrester.

The lightning strikes at the substations often lead to insulation breakdown, shattering of insulators and burnout of equipment especially at the outdoor substation; thus the electrical appliances connected to the network often experience poor power quality which is the outcome of the disturbance often refer to as the harmonics in the network. In which case, it ultimately results in downtime of the network and economic losses.

This paper has identified that the network design by the distribution engineers should match the arresters for lines and transformers in such a way as to ensure network stability during the thunderstorm incidence. Also, the arresters should never be by-passed in the connection of the network topology. This will result in fast response to attenuation during surge occurrence in the network. It is suggested that harmonic filters could be incorporated to the distribution networks to further improve in the elimination of the harmonics. So also, efforts should be made to attenuate lightning surges at lower voltage levels since network connection, at this stage, is more susceptible to the destructive effects of lightning surge.

\section{ACKNOWLEDGMENT}

The authors acknowledge the support of the management and staff of EKO ELECTRIC DISTRIBUTION COMPANY (EKEDC) for provision of data used in carrying out this work.

\section{REFERENCES}

[1] Anderson, J. G., Transmission Line Reference Book $345 \mathrm{kV}$, Electric Power Research Institute, 2nd edition, Palo Alto, USA, 1987.
[2] Oluseyi, P. O., Akinbulire, T. O. and Awosope, C. 0. A.; Solving the technical problems facing electrical energy development in Nigeria, UNILAG fair and conference, 2007 (Poster Presentation).

[3] Pereira, C. S., Almeida, A.d.C., Rocha, B.R.P., Frota, W.M., "Transmission line vulnerability to lightning over areas of dense rainforests and large rivers in the Amazon region", Electric Power Systems Research, 119 (2015), pp 287-292.

[4] Christodoulou, C. A., Ekonomou, L., Fotis, G. P., Harkiolakis, N., Stathopulos, L. A., "Optimization of Helenic overhead high-voltage transmission lines lightning protection", Energy, 34, pp 502-509, 2009.

[5] Oluseyi, P. O., Adelaja, T. S. and Akinbulire, T. O., "Analysis of the Transient Stability Limit of Nigeria's 330kV Transmission sub-network", Nigeria Journal of Technology, pp. 213-226, 2017.

[6] Zhou, Q., Liu, C., Bian, X., Lo, K. L., Li, D. “Numerical analysis of lightning attachment to wind turbine blade", Renewable Energy, 116, 584-593, 2018.

[7] Piatini, J., "Lightning protection of overhead power distribution lines", International Conference on Lightning Protection, $23^{\text {rd }}-26^{\text {th }}$ June, Uppsala, Sweden, 2008,

[8] Ali, S. A., "Design of Lightning Arresters for Electrical Power Systems Protection", Advances in Electrical and Electronics Engineering Power Engineering and Electrical Engineering, Vol. 11, No. 6, pp 433-442, 2013

[9] Mousa, A. M. and Srivastava, K. D., "A revised electrogeometric model for the termination of lightning strokes on ground objects", in proceedings of International Aerospace and Ground Conference on Lightning and Static Electricity, Oklahoma City, pp 342-352, 1988.

[10] Vita, V., Ekonomou, L. and Christodoulou, C. A., "The impact of distribution generation to the lightning protection of modern distribution lines", Energy Systems, Volume 7, Issue 2, pp 357-364, 2016.

[11] National Lightning Safety Institute, "Lightning Costs and Losses from Attributed Sources", http://lightningsafety.com/nlsi lls/nlsi annual us a losses.html

[12] Rodrigues, R. B., Mendes, V. M. F. and Catalao, J.P.S., "Protection of interconnected wind turbines against lightning effects: Overvoltages and electromagnetic transients study", Renewable Energy, vol. 46, pp 232-240, 2012.

[13] Nor, N. M., Abdullah, R., Rajab, R. and Ramar, K., "Field tests: Performance of practical earthing 
systems under lightning impulses", Electrical Power and Energy Systems, 43, 013, pp 223-228.

[14] Trainba, M. and Ekonomou, L., "Lightning performance of a HV/MV substation", Recent Advances on Energy and Environment, 26-32.

[15] Nafari, M., Gharehpetian, G. B. and Nikami, T., A novel parameter estimation method for metal oxide surge arrester models, Sadhan, (Indian Academy of Science) Vol. 36, Part 6, December, pp. 941-961, 2011.

[16] Fernandez F, Diaz R., "Metal oxide surge arrester model for fast transient simulations" Int. Conf. on Power System Transients, IPAT'01, Rio De Janeiro, Brazil, pp. 144-145, 2001.

[17] Wang, D., He, B., Zhong, W., Lin, B. Wang, D. and Li, T., "Application and Analysis for Surge Arrester on Lightning Protection of Distribution Network", https://www.matecconferences.org/articles/.../pdf/.../matecconf_icm es2016 07010.pdf. Accessed on November 6, 2017.

[18] Ribic, J., "Impact of line length on the operation of overvoltage protection in L V networks", Electric Power Systems Research, 121, 216-226, 2015.
[19] Verho, P., Marttila, M., Kannus, K., Pylvanainen, J. and Pouttu, M., "Optimization of overvoltage protection of distribution networks", 19th International Conference on Electricity Distribution, CIRED 2007 Session 5 Paper No 0616, Vienna Austria, 21-24 May, pp. 1-4, 2007.

[20] Begovic, M. M. (ed.), Electrical transmission system and smart Grid: Selected entries from Encyclopaedia of Sustainability Science and Technology, Springer, New York, 2013.

[21] Araujo, M. A., Flauzino, R. A., Altafim, R. A. C., Batista, 0. E. and Moraes, L. A., "Practical methodology for modelling and simulation of a lightning protection system using metal-oxide surge arresters for distribution lines", Electric Power Systems Research, 118, 47-54, 2015.

[22] Peppas, G. D., Naxakis, I. A., Vistas, C. T. and Pyrgioti, E. C., "Surge arresters' models for fast transients", 2012 IEEE International Conference on Lightning Protection, Vienna, Austria, 2-7 Sept, 2012, $\quad$ http://ieeexplore.ieee.org/abstract Ldocument. Accessed on November 6, 2017. 